\section{Communication Ability}

\author{
Jon G. Lyon ${ }^{1}$ and Sarah Wallace ${ }^{2}$ \\ ${ }^{1}$ Mazomanie, WI, USA \\ ${ }^{2}$ Rangos School of Health Sciences, Speech- \\ Language Pathology, Duquesne University, \\ Pittsburgh, PA, USA
}

\section{Definition}

Commonly refers to the ease, efficiency, and accuracy of the exchange of information or content between parties regardless of form, that is, communication may occur in the following forms: speaking; writing; listening; gesturing; seeing; drawing, pointing to pictures, letters, and words; or selecting messages on computerized augmentative and assistive communication devices. Human communication relies primarily on the preservation and maintenance of key social and interpersonal bonds (i.e., staying close and connected with individuals who matter most in daily life). Thus, effective communication depends as much on nonverbal behaviors such as facial expression, touch, and vocal intonation as on the exchange of words. Acquired communication deficits can occur in the absence of a notable loss in intelligence or nonlinguistic cognitive functions due to a loss of language ability, impaired motor speech skills, or voice disorders (e.g., aphasia, dysarthria, dysphonia/aphonia, and apraxia of speech).

\section{Cross-References}

Language

Speech

\section{References and Readings}

Beukelman, D., \& Mirenda, P. (2013). Augmentative and alternative communication: Supporting children and adults with complex communication needs (4th ed.). Baltimore: Paul H. Brookes. 